\title{
Vorwort.
}

Was ich hier gebe, kann gewissermaßen als eine neue, nur freilich um mehr als das Dreifache erweiterte Ausgabe meiner Abhandlung „Über den Creatianismus des Aristoteles" bezeichnet werden. Seit langem hatte sich das Bedürfnis nach einer solchen fühlbar gemacht. Im Jahre 1882 in den Sitzungsberichten der Wiener Akademie veröffentlicht, war sie in ihren wenigen Separatabzügen rasch vergriffen, und das gleiche gilt von der Gegenschrift, die Zeller in den Abhandlungen der Berliner Akademie noch in demselben Jahre ihr folgen lieB. Diese ist nun im ersten Bande der Sammlung von Zellers „Kleine Schriften“ bei Reimer neu erschienen. Und so dürfte es denn selbst denjenigen, welche Zellers Auffassung für die richtige halten, erwünscht sein, wenn auch die Schrift, auf welche er sich hier fort und fort bezieht, allgemeiner zugänglich gemacht wird.

Die Berücksichtigung, welche ein so namhafter Forscher meinen Ausführungen zuteil werden lieB, war in hohem Grade dankenswert. Man darf sagen, daB alles, was von gegnerischem Standpunkt geltend gemacht werden kann, durch seine Einwände erschöpft ist. Manche erscheinen auch wohl geeignet, einen starken Eindruck zu machen, aber eben darum wird auch die Richtigkeit der von mir vertretenen Auffassung durch nichts mehr als durch ihre Widerlegung gesichert. Ein zweiter Teil, den ich dieser Neuausgabe beifüge, beschäftigt sich damit, für jeden einzelnen die Lösung zu geben, indem er nicht selten 
zugleich AnlaB nimmt, die für die eigene Ansicht schon erbrachten Beweisgründe durch ganz neue Momente zu vermehren.

Auch in dem ersten Teile wurden einige Änderungen notwendig befunden, welche die frühere Darstellung berichtigen. Es geschah dies allerdings nur in untergeordneten Punkten, dürfte aber doch nicht unwichtig sein, um gewisse Bedenken vollständig zu beheben. Dabei unterlieB ich es in keinem Falle, die Abweichung von dem früheren Texte, wie er Zeller bei der Abfassung seiner Schrift „Über die Lehre des Aristoteles von der Ewigkeit des Geistes" vorgelegen, namhaft zu machen.

\section{Franz Brentano.}

